\title{
Differential Modulation of Proliferation in the Neocortical Ventricular and Subventricular Zones
}

\author{
Tarik F. Haydar, Feng Wang, Michael L. Schwartz, and Pasko Rakic
}

Section of Neurobiology, Yale University School of Medicine, New Haven, Connecticut 06510

Recent studies have implicated the classical neurotransmitters GABA and glutamate in the regulation of neural progenitor proliferation. We now show that GABA and glutamate have opposite effects on the two neural progenitor populations in the ventricular zones (VZs) and subventricular zones (SVZs) of the embryonic cerebrum. Application of either molecule to organotypic slice cultures dramatically increases proliferation in the VZ by shortening the cell cycle, whereas proliferation in the SVZ is decreased. These disparate effects, measured both by bromode- oxyuridine uptake and the expansion of retrovirally labeled progenitor clones, are mimicked by the application of specific GABA and glutamate agonists and are blocked by antagonists. Thus, the relative contributions of the VZ and SVZ to neocortical growth may be regulated by differential responsiveness to GABA and glutamate.

Key words: neurogenesis; neurotransmitter; progenitor; cell cycle; cerebral cortex; corticogenesis
Differences in neural progenitor cell proliferation may underlie the variations in cortical size between species as well as some of the neocortical malformations that are present in various neuropathological conditions (Rakic, 1988; Haydar et al., 1999b; Walsh, 1999). Both cell-intrinsic and -extrinsic factors contribute to changes in cell production and affect cerebral cortical growth. Recently, several extracellular molecules, such as grow th factors and neurotransmitters, have been implicated in the extrinsic regulation of cell proliferation in the developing telencephalon (for review, see Cameron et al., 1998). For example, basic fibroblast growth factor (bFGF), when added either to cultured cells or microinjected into embryonic brains, prolongs the proliferation of cortical progenitors, leading to increases in the numbers of cortical neurons (Gensburger et al., 1987; Cattaneo and McKay, 1990; Ghosh and Greenberg, 1995; Vaccarino et al., 1995; Cavanagh et al., 1997; Vaccarino et al., 1999). In contrast, the neurotransmitters GABA and glutamate reportedly reduce the number of proliferating cells in dissociated or organotypic cultures of the neocortex (LoTurco et al., 1995). Furthermore, GABA can partially block the bFGF-induced increase in proliferation (Antonopoulos et al., 1997). However, GABA was also shown to promote cell proliferation in cultures of cerebellar progenitors (Fiszman et al., 1999). Thus, it is unclear whether GABA and/or glutamate affect all neural progenitor cells in a similar manner or if these modulatory molecules affect cell proliferation differently in various brain regions. It is also unknown whether specific progenitor subpopulations in the same region are differentially affected during neurogenesis.

We have addressed these conceptually and practically important questions in the mammalian neocortex because it develops from two distinct proliferative populations, the ventricular zone (VZ) and subventricular zone (SVZ). The VZ lines the lateral ventricles and forms first, followed by the SVZ, which emerges superficial to the VZ (Boulder Committee, 1970). These two zones also differ in the behavior of their constituent cells. Progenitors within the VZ proliferate in a stereotypical manner termed interkinetic nuclear migration, in which DNA is replicated deep within the VZ, whereas

Received Jan. 11, 2000; revised May 4, 2000; accepted May 5, 2000.

This work was supported by National Institutes of Health Grants P01 NS22807 and P01 NS354765 and also by Grant F32 NS10729 to T.H.

Correspondence should be addressed to Dr. Pasko Rakic, Section of Neurobiology, SHM C-303, Yale University School of Medicine, 333 Cedar Street, New Haven, CT 06510. E-mail: pasko.rakic@yale.edu.

Copyright (C) 2000 Society for Neuroscience $0270-6474 / 00 / 205764-11 \$ 15.00 / 0$ cell division always occurs at the surface of the lateral ventricle. In contrast, SVZ cells do not exhibit movements as they divide but proliferate in situ without nuclear translocation (for review, see Sidman and Rakic, 1973; Takahashi et al., 1995b). Differences between these two proliferative populations are further underscored by eventual fate. The VZ is a transient embryonic structure that is ultimately replaced at the end of neurogenesis by ependymal cells with limited proliferative capacity in adulthood. Conversely, the SVZ [postnatally termed the subependymal zone (SEZ)] persists as a proliferative population throughout the remaining life span (Smart, 1961). Finally, although the VZ and SVZ intermingle at the most superficial extent of the VZ during prenatal development, the generative potential of these two populations is thought to be different, with progenitors in the VZ generating mainly neurons (Sidman et al., 1959) and progenitors in the SVZ/SEZ predominantly generating glial cells and a limited repertoire of neurons (Altman, 1969; Reynolds and Weiss, 1992; Doetsch et al., 1999).

Despite the cytological, functional, and developmental differences between the VZ and SVZ progenitors, little is known about the controls of cell proliferation in these two compartments and how they contribute to cortical growth. In the present study, we have used an organotypic slice culture that maintains the spatial separation between the VZ and SVZ to examine how GABA and glutamate affect the proliferative behavior of cells in these two zones. The results reveal inherent differences between $\mathrm{VZ}$ and SVZ progenitors in their physiological response to the same molecules.

\section{MATERIALS AND METHODS}

Generation of neocortical organotypic slices. Embryonic day 13 (E13) and E14 ICR strain (Harlan Sprague Dawley) mouse fetuses were used for all slice experiments. Slices were prepared as described previously (Haydar et al., 1999a). Briefly, brains were dissected and collected in cold HEPESbuffered MEM (Life Technologies, Gaithersburg, MD). The brains were sliced into $300 \mu \mathrm{m}$ coronal slices on a McIlwain tissue chopper and then transferred back into MEM media, in which slices were separated with forceps under a dissecting microscope. Intact coronal slices at the level of the future sensorimotor cortex were hemisected and then transferred to collagen-coated tissue culture inserts (Corning Costar Transwell; catalog \#3494) containing Neurobasal medium supplemented with B27, L-glutamine, and N2 (Life Technologies). Slices were arranged flat, the level of media was lowered to form a meniscus just above the slices, and the slices were then cultured in an incubator at $37^{\circ} \mathrm{C}$ in $5 \% \mathrm{CO}_{2}$. After $4 \mathrm{hr}$ incubation to allow for recovery, 5-bromo-2'-deoxyuridine (BrdU) $(0.25 \%$ 

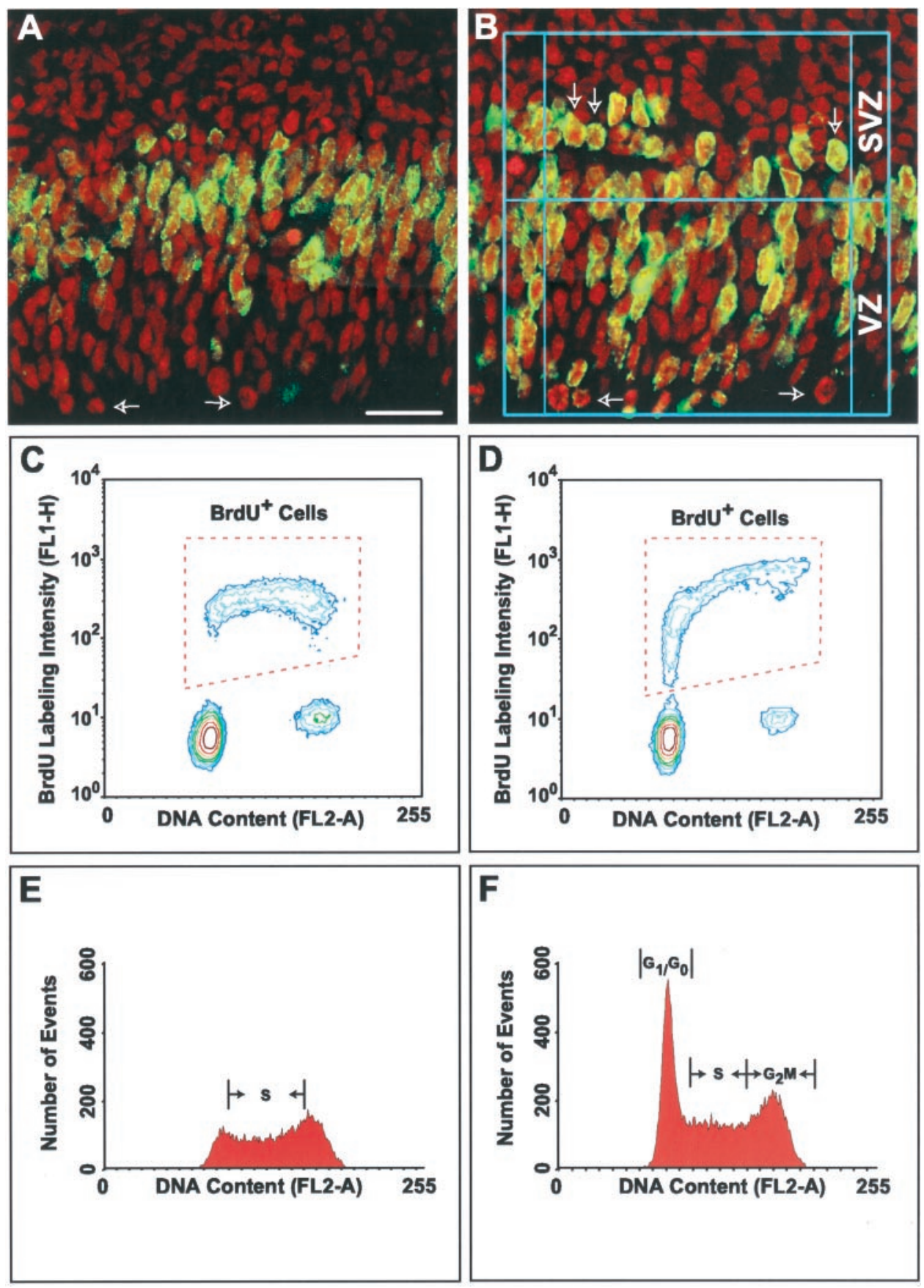

Figure 1. VZ cells in the organotypic slices undergo interkinetic migration as they progress through the cell cycle. $A$, Cells in S-phase form an abventricular $\mathrm{BrdU}^{+}$band in the VZ after $1 \mathrm{hr}$ labeling with BrdU (surface of lateral ventricle is at bottom). $B$, After $8 \mathrm{hr}$ of cumulative BrdU labeling, many originally labeled S-phase cells have migrated to the apical surface of the VZ and are dividing. In addition, as more unlabeled cells enter S-phase and incorporate BrdU, the $\mathrm{VZ}$ begins to fill with $\mathrm{BrdU}^{+}$cells. $C, E$, After $1 \mathrm{hr}$ of BrdU labeling, flow cytometric analysis shows $\mathrm{BrdU}^{+}$cells in S-phase of the cell cycle. Cells in S-phase for the entire period of labeling have a high DNA content, whereas cells in S-phase for a short period of time have lower DNA content. $D, F$, After 8 $\mathrm{hr}$ of labeling, $\mathrm{BrdU}^{+}$cells are spread throughout the cell cycle. Some cells that were labeled at the end of S-phase have progressed through mitosis and are now in G1/G0 phase. final concentration; Sigma) was added to the culture medium and was present for the remainder of the experiment. The pharmacological agents (in $\mu \mathrm{M}$ ): 30 GABA, 50 glutamate, 30 muscimol, 150 kainate, 10 bicuculline (BMI) (Sigma, St. Louis, MO), and 10 6-cyano-7-dinitroquinoxaline-2,3dione (CNQX) (Research Biochemicals, Natick MA) were added to the media before addition of the slices at the start of the $4 \mathrm{hr}$ recovery period. The concentrations were used based on dose-response curves published previously (LoTurco et al., 1995).

After culturing for variable time periods, slices were fixed overnight in $4 \%$ paraformaldehyde and cryoprotected in $30 \%$ sucrose. Slices were then resectioned in $20 \mu \mathrm{m}$ increments in the coronal plane with a cryostat. The middle three frozen sections of each slice were stained (see below). The central $10 \mu \mathrm{m}$ of these sections was then optically sectioned in the coronal plane into a stack of $10 \times 1 \mu \mathrm{m}$ images using a Zeiss LSM 510 confocal microscope. Image stacks were assembled to construct an optical dissector in which nuclei contained within the depth of the stack were counted with a $100 \times 125 \mu \mathrm{m}$ (width $\times$ height) box (Fig. $1 B$ ). This box was horizontally transected at a height of $70 \mu \mathrm{m}$. VZ nuclei were counted within the bottom $70 \mu \mathrm{m}$, and SVZ cells were counted within the top $55 \mu \mathrm{m}$ (Fig. $1 B$ ). The boundary between the VZ and SVZ was determined both by the position of the deepest abventricular mitotic figure and the bottom of the band of SVZ cells after BrdU pulse chase experiments analyzed when the labeled
VZ cells had migrated to the ventricular surface (data not shown). This position was at $70 \mu \mathrm{m}$ above the ventricular surface throughout all experiments. Cell counts were analyzed in a double-blind fashion with respect to culture conditions. Counts of neocortical slices were consistently made midway between the medial and lateral angles of the lateral ventricle at the level of the future sensorimotor cortex (for example, see Schambra et al., 1992, their plate GD14, COR. 5).

BrdU slice proliferation assays. The proliferative characteristics of slice VZ cells was assayed both by morphology (mitotic figures) of proliferating cells as well as with BrdU incorporation into cells in S-phase of the cell cycle. BrdU-labeled nuclei were visualized using an anti-BrdU antibody (1:77, overnight at $4^{\circ} \mathrm{C}$; Becton Dickinson, Mountain View, CA) coupled to an anti-mouse $\operatorname{IgG}_{1}$-FITC (1:200, 1 hr RT; Southern Biotechnology Associates, Birmingham, AL) secondary antibody. Propidium iodide $(1 \times$ $10^{-4} \%$; PI) was used as a counterstain to visualize the DNA of all cells. The labeling index ( $\mathrm{LI}$; percentage of $\mathrm{BrdU}^{+}$cells of total $\mathrm{VZ}$ cells) after variable BrdU exposure times was determined by cell counting as detailed above.

Cell cycle analysis. The duration of the cell cycle in the slice VZ was estimated as described previously (Takahashi et al., 1995a; Haydar et al., 1999b). Briefly, slices incubated in the presence of BrdU for increasing periods of time were then processed for BrdU immunohistochemistry. 

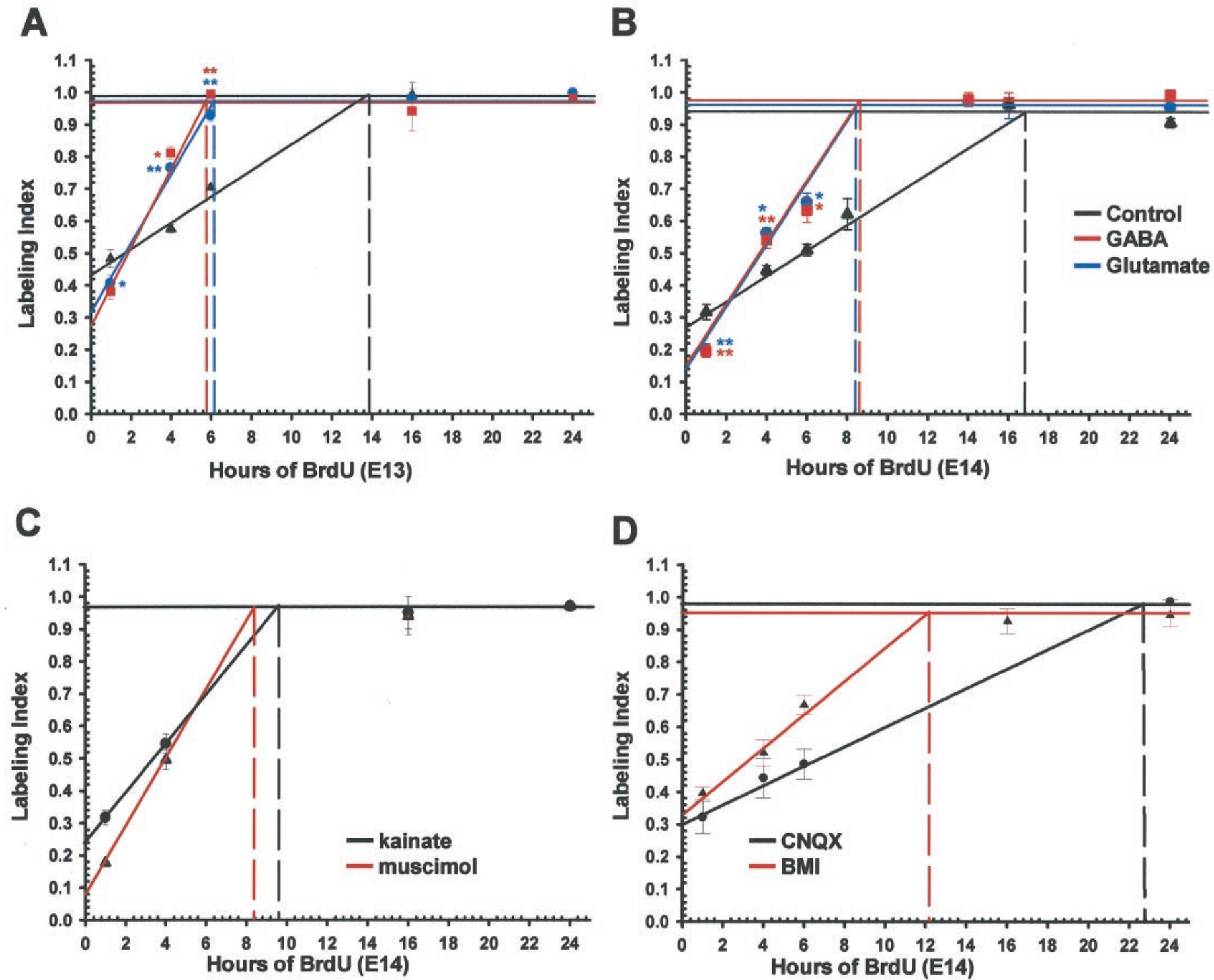

Figure 2. GABA and glutamate increase proliferation in the VZ. A, In slices cultured at E13, the LI rises steadily in control slices (black lines) as VZ cells progress through the cell cycle and are labeled with BrdU. In contrast, the LI curves for GABA $(30 \mu \mathrm{M})$ - and glutamate $(50 \mu \mathrm{M})$-treated slices $($ red and blue lines, respectively) rise with a steeper slope, indicating that the cell cycle is faster in treated slices. B, Similarly, the cell cycle of GABA- and glutamate-treated slices is shorter than controls at E14. $C$, The addition of GABA and glutamate agonists to E14 slice cultures also increases the rate of VZ proliferation (compare to black curve in $B)$. D. Conversely, the GABA and glutamate antagonists BMI $(10 \mu \mathrm{M})$ and CNQX (10 $\mu \mathrm{M})$ tend to prolong the duration of the cell cycle. Interestingly, addition of CNQX to the slices increases the duration of the cell cycle when compared to controls (black curve in $B$ ).

Labeling indices were plotted (Fig. 2), and the cell cycle parameters were solved using the equation:

$$
Y=\left(\frac{G F}{T c}\right) * t+B
$$

where $T c$ is the duration of the entire cell cycle, $G F$ is the growth fraction or maximum number of proliferating cells in the VZ, and $t$ is the duration of BrdU application. In Figure 2, the LI plots reach a maximum value over time and then level off; the time when $Y_{\max }$ is reached reflects the duration of $T c-T s$, where $T s$ is the duration of S phase. The magnitude of $Y_{\max }$ also determines the $G F$.

Flow cytometry assays. The cultures were ended by placing slices into ice-cold MEM-HEPES. Neocortical areas were dissected out and collected. After two washes in ice-cold HBSS (Life Technologies), the samples were digested at $37^{\circ} \mathrm{C}$ for 20 min with $0.25 \%$ trypsin (Life Technologies) dissolved in HBSS. Digestion was stopped by adding an equal percentage of trypsin inhibitor (Sigma) on ice, and the samples were triturated with a fire-polished Pasteur pipette. The cells were fixed in cold $70 \%$ ethanol for at least $30 \mathrm{~min}$ and stored at $-20^{\circ} \mathrm{C}$. Approximately $1 \times 10^{6}$ fixed cells were centrifuged and resuspended in $2 \mathrm{~N} \mathrm{HCl}$ containing $0.5 \%$ Triton $\mathrm{X}-100$ for $30 \mathrm{~min}$. Cells were washed in $0.1 \mathrm{M} \mathrm{Na}_{2} \mathrm{~B}_{4} \mathrm{O}_{7} \cdot 10 \mathrm{H}_{2} \mathrm{O}$, $\mathrm{pH} 8.5$, for $10 \mathrm{~min}$ to neutralize the acid, and then incubated with anti-BrdU antibody solution (1:50 in blocking solution containing PBS, $0.5 \%$ Tween 20 , and $1 \%$ bovine serum albumin) overnight at $4^{\circ} \mathrm{C}$. After a PBS wash, cells were incubated $1 \mathrm{hr}$ in FITCconjugated sheep anti-mouse IgG (1:25 in blocking solution). Cells were washed in PBS and incubated at $37^{\circ} \mathrm{C}$ for $30 \mathrm{~min}$ with $1 \mathrm{mg} / \mathrm{ml}$ RNase A (Sigma) and then stained with $5 \mu \mathrm{g} / \mathrm{ml}$ PI (Sigma). Flow cytometric analysis was performed with a FACS Vantage flow cytometer (Becton Dickinson). The cells were excited at $488 \mathrm{~nm}$, and the emission was collected simultaneously through two bandpass filters $(530 / 30 \mathrm{~nm}$ and $630 / 22 \mathrm{~nm})$. A total of 100,000 cells was collected from each sample. The two-dimensional contour graph (BrdU vs PI) and the histogram of the BrdU-positive cell population (Fig. $1 C-F$ ) were plotted with WinMDI 2.7 software.

Immunohistochemistry. The distributions of GABA and gluta- 
mate were analyzed in fixed $20 \mu \mathrm{m}$ cryostat sections of the developing neocortical wall. Guinea pig anti-GABA primary antibody (Protos Biotech, New York, NY) was applied at 1:1000 to sections from brains fixed in $4 \%$ paraformaldehyde and was visualized using a FITC-conjugated secondary antibody (Southern Biotechnology Associates) used at 1:200 dilution. Rabbit anti-glutamate primary antibody (Arnel, Cherokee Station, NY) was applied at $1: 1000$ to sections from brains fixed in $4 \%$ paraformaldehyde/ $0.25 \%$ glutaraldehyde, and sections were then incubated in Cy2conjugated species-appropriate secondary antibody (Jackson ImmunoResearch, West Grove, PA) at 1:300. All sections were counterstained with PI $\left(1 \times 10^{-4} \%\right.$ in PBS; Sigma $)$. Images of stained sections were collected with a SPOT2 CCD camera on a Zeiss Axioplan2 microscope and were standardized with respect to the level of GABA and glutamate staining of cellular elements and the propidium iodide staining. Confocal images $(1 \mu \mathrm{m}$ single optical sections) were collected on a Zeiss LSM510 and were similarly standardized.

Surgical procedures and retroviral labeling. Retroviral DNA (pLIA) (Bao and Cepko, 1997; Furukawa et al., 1997) encoding the alkaline phosphatase gene was introduced into the Phoenix viral packaging cell line by transfection using calcium phosphate (Pear et al., 1996). Viral particles were collected from the supernatants of these cultures, concentrated in Centricon tubes, and were titered at $1.2 \times 10^{7} \mathrm{cfu} / \mathrm{ml}$ before being stored in aliquots at $-80^{\circ} \mathrm{C}$ until use. Pregnant dams at $14 \mathrm{~d}$ gestation were anesthetized with ketamine $(100 \mathrm{mg} / \mathrm{ml})$ and xylazine $(20 \mathrm{mg} / \mathrm{ml})$. The uterine horns were exposed by midline incision, and embryos were visualized through the uterine wall by transillumination from a fiber optic light source. One microliter of pLIA virus/fast green ( $0.1 \%$ in phosphate buffer) mixture (10:1) was injected into the lateral ventricles using a picoinjector (Medical Systems Corporation, Greenvale, NY). The uterus was then replaced into the abdominal cavity, and the incisions were sutured closed. After $24 \mathrm{hr}$, neocortical slices were cultured from each embryo as detailed above. Some slices were also cultured in the presence of GABA or glutamate for $24 \mathrm{hr}$, and then slices were stained for alkaline phosphatase (AP) activity using nitro blue tetrazolium/5-bromo-4-chloro-3-indolyl phosphate (NBT/BCIP). Briefly, slices were fixed in $4 \%$ paraformaldehyde overnight and sunk in $30 \%$ sucrose. Serial sections $(25 \mu \mathrm{m})$ were cut on a cryostat and washed with PBS, $\mathrm{pH} 7.4$, before endogenous phosphatases were inactivated at $65^{\circ} \mathrm{C}$ for $30 \mathrm{~min}$. Sections were then incubated in NBT/BCIP (Boehringer Mannheim, Mannheim, Germany) per manufacturer's instructions for $24 \mathrm{hr}$, rinsed for $1 \mathrm{hr}$ in PBS, and then mounted using 30\% glycerol in PBS. Labeled clusters, defined as immediately adjacent cells (the only type of labeled cells), were sparse and widely separated in infected brains. The number of neocortical clusters averaged $8 \pm 2.36$ (mean \pm SEM) per brain, with one or two clusters per individual brain section.

Migration analysis. The migration of neocortical cells out of the $\mathrm{VZ}$ after cell division was determined by measuring the number of $\mathrm{BrdU}^{+}$cells present outside of the germinal zones after increasing periods of time. BrdU was added to slices for either 24 or $48 \mathrm{hr}$. The number of $\mathrm{BrdU}^{+}$cells that were present superficial to the $\mathrm{VZ}$ and SVZ was then determined to measure how many postproliferative cells had exited the cell cycle and migrated up into the neocortical wall. The superficial border of the SVZ was determined empirically for each slice as a line parallel to the ventricular surface at the level of the most superficial abventricular mitotic figure.

\section{RESULTS}

\section{GABA and glutamate increase cell proliferation in the VZ}

To analyze the effect of GABA and glutamate on the proliferation of different populations of neural progenitors, we used organotypic slices of the embryonic cerebral wall which, when cultured in minimal defined media, maintained the morphological separation between the $\mathrm{VZ}$ and $\mathrm{SVZ}$ as well as the respective behaviors of

\begin{tabular}{lcccl}
\hline Table 1. E13 cell cycle & & & & \\
& Tc & Tc-Ts & Ts & GF \\
\hline In vivo & 11.4 & 7.5 & 3.9 & 1 \\
Control & 22.4 & 13.9 & 8.5 & 0.99 \\
GABA $30 \mu \mathrm{M}$ & 8.8 & 6 & 2.8 & 0.97 \\
Glutamate $50 \mu \mathrm{M}$ & 8.1 & 5.8 & 2.3 & 0.97 \\
\hline
\end{tabular}

\begin{tabular}{lcccl}
\hline Table 2. E14 cell cycle & & & & \\
& Tc & Tc-Ts & Ts & GF \\
\hline In vivo & 15.1 & 11.3 & 3.8 & 1 \\
Control & 25 & 16.8 & 8.2 & 0.94 \\
BMI $10 \mu \mathrm{M}$ & 20 & 12.2 & 7.8 & 0.95 \\
CNQX $10 \mu \mathrm{M}$ & 33 & 22.7 & 10.3 & 0.99 \\
GABA $30 \mu \mathrm{M}$ & 10 & 8.6 & 1.4 & 0.98 \\
Glutamate $50 \mu \mathrm{M}$ & 10 & 8.4 & 1.6 & 0.96 \\
Muscimol $30 \mu \mathrm{M}$ & 9.4 & 8.4 & 1 & 0.97 \\
Kainate $150 \mu \mathrm{M}$ & 13.1 & 9.6 & 3.6 & 0.97
\end{tabular}

Values for in vivo cell cycle phase durations were taken from Takahashi et al. (1995a). Tc, Cell cycle duration; Tc-Ts, the cumulative duration of G2, M, and G1 phases; Ts, S-phase duration; GF, growth fraction (percentage of proliferating VZ cells).

these populations during proliferation (Haydar et al., 1999a). In particular, by combining BrdU labeling (Fig. $1 A, B$ ) and flow cytometric analyses (Fig. $1 C-F$ ), it was evident that VZ cells underwent interkinetic nuclear migration as they progressed through the cell cycle, whereas SVZ cells did not. In addition, the slice cultures maintained the separation between the proliferative zones and differentiated neurons and glia, and cells in the slices survived well up to $72 \mathrm{hr}$ in culture (Haydar et al., 1999a).

Using cumulative BrdU labeling, we determined that the VZ cell cycle duration (Tc) for E13 and E14 control slices was 22.4 and 25 hr, respectively (Fig. 2A,B, Tables 1,2 ). As observed previously (Takahashi et al., 1999), the length of the cell cycle in vitro was longer than durations reported for corresponding ages in vivo. Nevertheless Tc from E13-E14 cultured slices was similar to the increase in Tc reported in vivo for the VZ (Takahashi et al., 1995a). This increase of Tc in the slice was not attributable to a change in the duration of S-phase (Ts), which remained relatively constant at $\sim 8.5 \mathrm{hr}$ in controls, but rather was attributable to the lengthening of the remaining cell cycle phases (Tc-Ts) (Tables 1,2). This corresponds to the increase of Tc in vivo which is attributable to progressive lengthening of G1 phase (Takahashi et al., 1995a).

To determine the effect of GABA and glutamate on the proliferation of $\mathrm{VZ}$ cells, slices were cultured in the presence of both BrdU and either of the two neurotransmitters. Both neurotransmitters reduced the cell cycle duration of VZ cells; exogenously applied GABA $(30 \mu \mathrm{M})$ reduced Tc in the E13 VZ to $8.8 \mathrm{hr}$, whereas Tc at E14 was $10 \mathrm{hr}$. Similarly, glutamate $(50 \mu \mathrm{M})$ also shortened Tc in the E13 VZ to $8.1 \mathrm{hr}$ whereas the E14 Tc was shortened to $10 \mathrm{hr}$. Notably, all phases of the cell cycle in neurotransmitter-treated slices were reduced to between 50 and $80 \%$ of control values (Fig. $2 A, B$, Tables 1,2 ).

To determine the specific receptors underlying the effects of GABA and glutamate on VZ proliferation, we applied pharmacological agonists and antagonists of $\mathrm{GABA}_{\mathrm{A}}$ and $\mathrm{AMPA} /$ kainate glutamate receptors to the culture medium in the place of GABA and glutamate. Like GABA and glutamate themselves, GABA and glutamate agonists also increased $\mathrm{VZ}$ proliferation. Muscimol $(30 \mu \mathrm{M}), \mathrm{a} \mathrm{GABA}_{\mathrm{A}}$ receptor agonist, decreased the VZ Tc by $62 \%$. A similar decrease was found for other cell cycle phase durations (Fig. 2D, Table 2). Kainic acid (KA) $(150 \mu \mathrm{M})$, an AMPA/kainate receptor agonist, reduced the slice Tc by $48 \%$, whereas Tc-Ts was reduced by $43 \%$, and Ts was reduced by $56 \%$ (Fig. 2D, Table 2). 
Moreover, BMI $(10 \mu \mathrm{M})$ and CNQX $(10 \mu \mathrm{M})$, antagonists of $\mathrm{GABA}_{\mathrm{A}}$ and AMPA/kainate glutamate receptors, respectively, did not significantly decrease Tc. In the case of CNQX, Tc was even longer than in controls suggesting the presence of endogenous glutamate in the slice cultures (Fig. 2C, Table 2). Taken together, these results indicate that exogenously applied GABA and glutamate shorten the cell cycle of $\mathrm{VZ}$ progenitors, and that this effect is mediated by $\mathrm{GABA}_{\mathrm{A}}$ or AMPA/kainate receptors.

\section{GABA and glutamate increase the size of VZ clones}

The cell cycle experiments described above used a population approach to measurement of the GABA and glutamate effects on the entire VZ progenitor pool. To determine how the neurotransmitters influence the clonal expansion of individual progenitors, the number of $\mathrm{VZ}$ cells in retrovirus-infected progenitor clusters was used as an indicator of the number of cell divisions over time (Fig. 3). Embryos were injected intracerebrally with a low concentration of retrovirus containing the reporter gene alkaline phosphatase (AP) to yield widely separated infected VZ progenitors. The number of cells per cluster after 24 and $48 \mathrm{hr}$ of infection in vivo was measured to determine whether this method is useful for following the number of cell divisions per cluster. Because retroviral DNA can only integrate during a mitotic division, with only one daughter cell receiving the viral DNA, after a single division only one cell should be labeled (Hajihosseini et al., 1993). The number of $\mathrm{AP}^{+}$cells per cluster should then grow exponentially as the originally labeled cell divides further. As expected, embryos injected on E13 and analyzed 24 hr later, which allowed less than two cell cycles to elapse (Takahashi et al., 1995a), had $1.25 \pm 0.25$ cells per cluster (mean \pm SEM, 15 clusters). In contrast, clusters were either two or four cells $48 \mathrm{hr}$ after infection (2.84 \pm $0.19,31$ clusters), which is enough time for a maximum of three cell cycles (Fig. 3). Thus, we found that the number of cells/cluster is consistent with the mitotic history within the cluster.

To determine the effects of GABA and glutamate on $\mathrm{AP}^{+}$ cluster size, E13 embryos were infected with pLIA for $24 \mathrm{hr}$, and neocortical slices were then cultured in the presence or absence of GABA and glutamate. After $24 \mathrm{hr}$ of additional in vitro incubation, the VZ cluster size in control slices was still only one or two cells $(1.42 \pm 0.23,24$ clusters) (Fig. $3 E)$. This is likely attributable to the length of Tc in E14 control slices $(\sim 25 \mathrm{hr}$, Table 2$)$. Thus, the one $\mathrm{AP}^{+}$cell resulting after the initial $24 \mathrm{hr}$ in vivo incubation (Fig. $3 B$ ) would be unable to complete another division during the $24 \mathrm{hr}$ of in vitro incubation. In contrast, $\mathrm{VZ}$ clusters in GABA and glutamate-treated slices consisted of either two or four cells after the second $24 \mathrm{hr}$ of incubation in vitro $(3.13 \pm 0.41,26$ clusters and $2.76 \pm 0.67,75$ clusters, respectively) (Fig. $3 F, G$ ). Thus, the number of $\mathrm{VZ}$ cells per cluster was significantly larger in GABA and glutamate-treated slices, further indicating that GABA and glutamate shorten the cell cycle of individual VZ progenitors resulting in more divisions compared to controls.

\section{GABA and glutamate decrease cell proliferation in the SVZ}

To determine how GABA and glutamate affect proliferation in the SVZ, we examined cell proliferation in the same slices used for the $\mathrm{VZ}$ analysis. Using cumulative BrdU labeling, the LI (percentage of $\mathrm{BrdU}^{+}$cells) in the SVZ $\left(\mathrm{LI}_{\mathrm{SvZ}}\right)$ steadily increased over time as proliferating cells replicated their DNA and incorporated BrdU (Fig. 4A, dashed line). GABA (purple line), glutamate (light red line), muscimol (dark green line), and KA (dark red line) all significantly decreased the number of $\mathrm{BrdU}^{+} \mathrm{SVZ}$ cells over time so that the $\mathrm{LI}_{\mathrm{SVZ}}$ did not rise normally. In contrast, BMI and CNQX application resulted in a positive rise in $\mathrm{LI}_{\mathrm{SVZ}}$ over time (Fig. $4 A$, light green and yellow lines), although the slope of the $\mathrm{LI}_{\mathrm{SVZ}}$ was slightly decreased compared to controls. Thus, surprisingly in contrast to the findings in the VZ, proliferation in the SVZ is markedly decreased in response to GABA, glutamate, and their agonists.

These data are partly in disagreement with previous studies
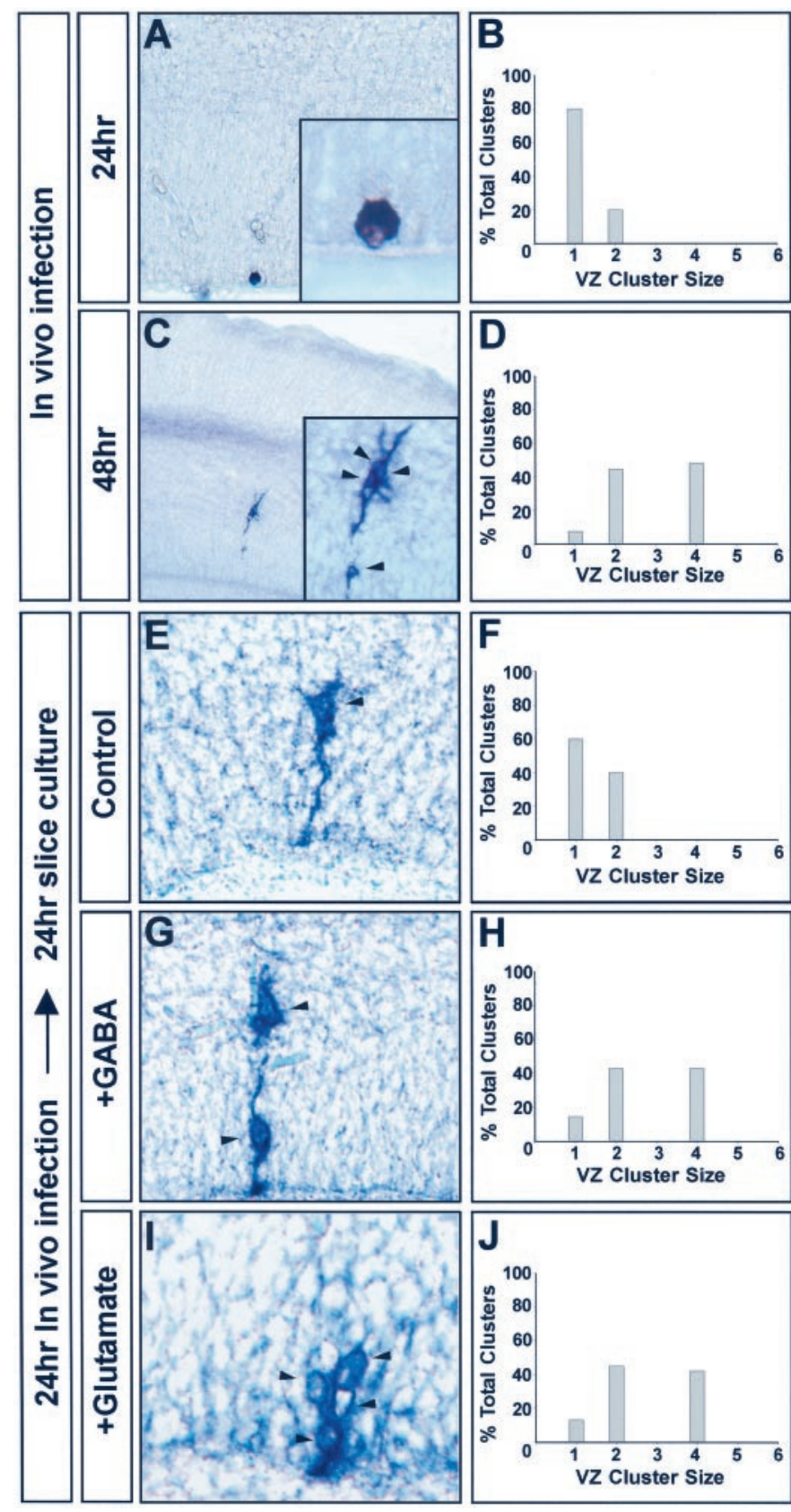

Figure 3. GABA and glutamate increase VZ cluster size. $A, B$, Because progenitors had only enough time to divide once under control conditions (Table 1), the number of pLIA-infected cells per cluster $24 \mathrm{hr}$ after retroviral infection of E13 embryonic brains was one cell per cluster. Image in $A$ shows a retroviral-infected $\mathrm{VZ}$ progenitor dividing at the surface of the lateral ventricle. $C, D$, By $48 \mathrm{hr}$ after infection in vivo, infected cells cultured under control conditions had divided two or three times yielding two or four cells per cluster. Inset in $C$ shows the cells in this cluster at higher magnification. $E, F$, In control slice cultures made $24 \mathrm{hr}$ after in vivo retroviral infection on E13 and then cultured for an additional $24 \mathrm{hr}$, there were one or two cells per cluster. $G, H$, GABA or $(I$ and $J$ ) glutamate application during the slice incubation caused VZ progenitors to divide more quickly, increasing the number of VZ cells/cluster to two or four cells.

suggesting that GABA and glutamate decrease the proliferation of neocortical progenitors (LoTurco et al., 1995; Antonopoulos et al., 1997). However, the distinction between the VZ and SVZ was not made in these studies because all progenitors were analyzed en masse. Therefore, we decided to examine whether GABA and glutamate caused a general decrease in proliferation if we treated the neocortical proliferative zones as a homogenous population. To accomplish this, we pooled the LI data for the VZ and SVZ together (Fig. 4). When the $\mathrm{LI}_{\mathrm{VZ}}$ was analyzed separately at either 


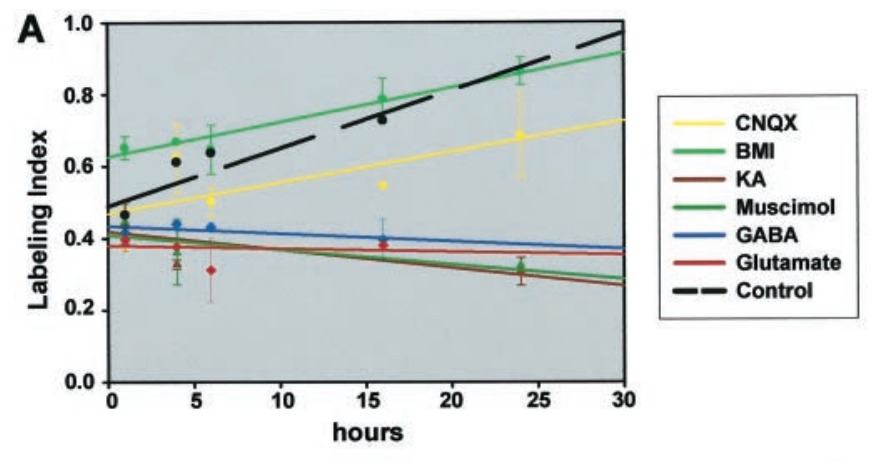

B

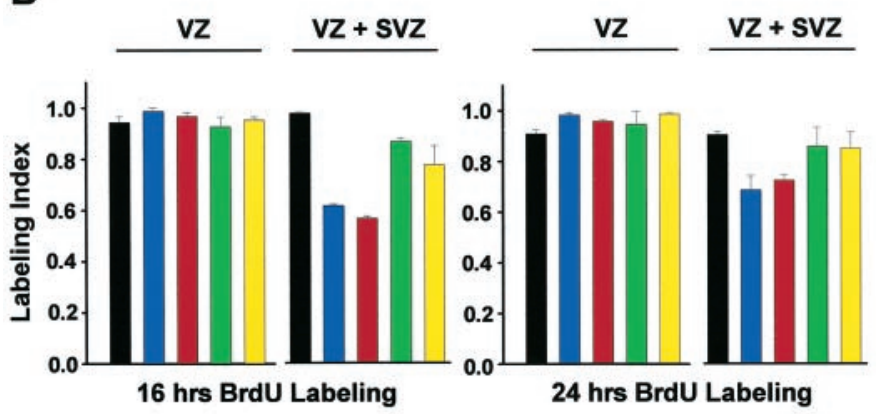

Figure 4. GABA and glutamate decrease SVZ proliferation. $A$, The LI in the E14 control slice SVZ increases steadily over time as more cells enter $\mathrm{S}$-phase and incorporate BrdU (dashed line). The GABA and glutamate antagonists BMI and CNQX also caused positive slopes in the SVZ LI curves ( green and yellow lines, respectively). In contrast, GABA, glutamate, and their agonists all cause no increase in the number of BrdU ${ }^{+} \mathrm{SVZ}$ cells over time, suggesting that SVZ proliferation is inhibited in response to GABA and glutamate. $B$, At 16 and $24 \mathrm{hr}$ of cumulative BrdU labeling in E14 slices, no difference in LI is seen in the VZ between control, GABA-, glutamate-, and antagonist-treated slices. In contrast, when the VZ and SVZ LIs at 16 and $24 \mathrm{hr}$ are pooled, GABA and glutamate decrease the combined LI and BMI and CNOX block this decrease. Thus, GABA and glutamate have an overall inhibitory affect on progenitor proliferation when the VZ and SVZ are analyzed together.

16 or $24 \mathrm{hr}$ of cumulative BrdU labeling, no effect was seen in response to GABA, glutamate, or their agonists and antagonists (Fig. 4B). This is likely attributable to the fact that all VZ progenitors had already passed through S-phase and incorporated BrdU and because the growth fraction (GF; or maximum number of proliferating VZ cells) was similar in treated and control conditions ( 95-99\%) (Fig. 2). In contrast, because the SVZ was not saturated with $\mathrm{BrdU}^{+}$cells, when the $\mathrm{LI}_{\mathrm{VZ}}$ and $\mathrm{LI}_{\mathrm{SVZ}}$ were pooled at 16 and $24 \mathrm{hr}$, significant differences were seen between control and neurotransmitter-treated groups. Specifically, exogenously applied GABA and glutamate caused a decrease in the $\mathrm{LI}_{\mathrm{VZ}+\mathrm{SVZ}}$ that could be blocked by BMI and CNQX, respectively (Fig. $4 B$ ). Thus, although the $\mathrm{LI}_{\mathrm{VZ}}$ was maximum for all experimental groups at these time points, the substantial decrease in SVZ proliferation due to GABA and glutamate overwhelmed the increase in the $\mathrm{VZ}$ and caused a general decrease in the combined $\mathrm{LI}_{\mathrm{VZ}+\mathrm{SVZ}}$.

\section{GABA and glutamate inhibit generation of postmitotic cells}

To test whether GABA and glutamate affect other parameters of cell proliferation in addition to modulating the cell cycle duration, we analyzed cell production and migration from the proliferative zones into the neocortical wall (Fig. 5). We previously showed that cells in our slice preparation exit the proliferative zones when they complete their last cell cycle (Haydar et al., 1999a). Therefore, during a cumulative BrdU-labeling experiment, the number of cells that migrate above the proliferative zones can be used as a measure of the amount of postmitotic cell production over time. After $24 \mathrm{hr}$ cumulative BrdU labeling on control E14 slice cultures, which

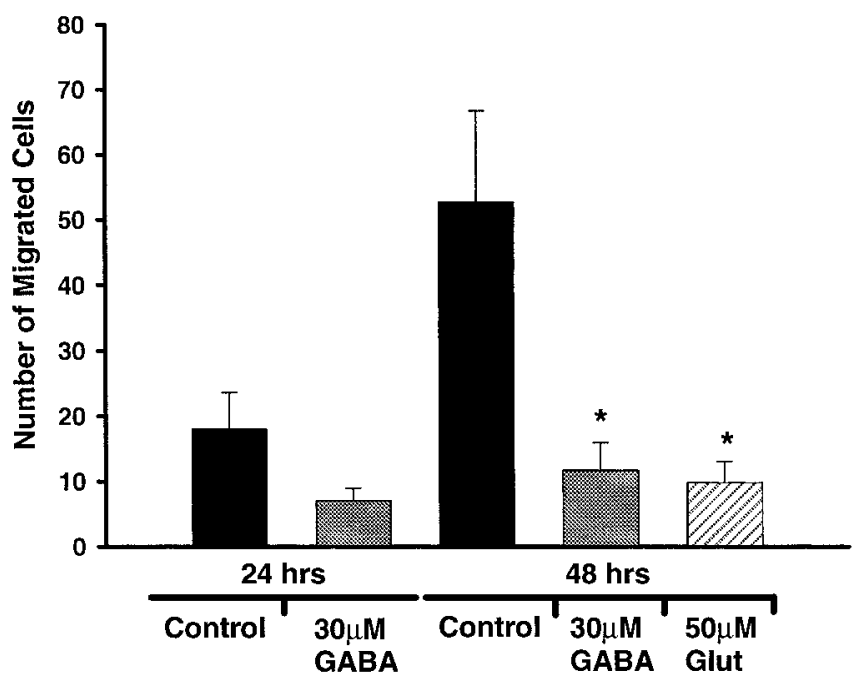

Figure 5. Postmitotic cell generation is inhibited by GABA and glutamate. The number of $\mathrm{BrdU}^{+}$cells from 24 or $48 \mathrm{hr}$ cumulative labeling experiments that had migrated into the neocortical wall above the SVZ were recorded for slices cultured on E14. After $24 \mathrm{hr}$, few BrdU ${ }^{+}$cells in control slices (black bar) had exited the cell cycle and migrated away from the VZ and SVZ. Similarly, few cells in GABA-treated slices had exited the proliferative zones even though VZ cells in treated slices (gray bar) had progressed through two cell cycles compared to the one cell cycle in controls (Table 2). After $48 \mathrm{hr}$ and two $\mathrm{VZ}$ cell cycles of labeling, many $\mathrm{BrdU}^{+}$cells had exited the proliferative zones in controls (black bar). In contrast, $80 \%$ fewer cells had migrated out of the proliferative zones in GABA- (gray bar) and glutamate- (striped bar) treated slices over the four cell cycles under those conditions (Table 2). ${ }^{*} p<0.01$.

roughly corresponds to the length of one in vitro cell cycle (Table 2 ), very few BrdU ${ }^{+}$cells had migrated above the overlying SVZ. However, even fewer $\mathrm{BrdU}^{+}$migratory cells were found in slices treated with GABA for $24 \mathrm{hr}$, although this time point corresponded to the length of two full cell cycles under these conditions (Table 2). Similarly, compared to controls, fewer $\mathrm{BrdU}^{+}$migratory cells were found in slices cultured in the presence of either GABA or glutamate after $48 \mathrm{hr}$, although VZ cells in neurotransmittertreated slices had divided twice as many times as controls during this period (four vs two cell divisions) (Table 2). These results indicate that GABA and glutamate reduce the generation of postmitotic cells. Specifically, the neurotransmitters may prevent exit from the cell cycle and thus keep VZ cells proliferating.

\section{Sources of GABA and glutamate in the embryonic cerebral wall}

In light of the previous and present results that GABA and glutamate can influence progenitor proliferation, we sought to determine the source and distribution of these two molecules. Several studies have previously identified GABAergic and glutaminergic cells in the neocortical wall during neurogenesis (Van Eden et al., 1989; Schwartz and Meinecke, 1992; Yan et al., 1992; Lidow and Rakic, 1995), and it is possible that these cells release their neurotransmitters into the proliferative zones. The released transmitter could diffuse long distances as well as be produced locally. Thus, to identify whether changes in the extracellular distribution of GABA and glutamate correlate with known neurogenetic gradients and therefore whether their diffusion accounts for the changes in neocortical proliferative kinetics, we used immunofluorescence in developmental series of neocortical brain sections. Similar to previous work (Yan et al., 1992), staining for GABA revealed a striking distribution that is dynamically regulated during the period of neurogenesis (Fig. 6). The first GABAergic cells were observed on E10 and were situated near the pial surface of the neuroepithelial wall. At this age there was diff use GABA stainingpresent throughout the neuroepithelium. By E12, GABAimmunoreactive cells were present in the preplate (cells of the future subplate and marginal zone), and diffuse GABA staining 

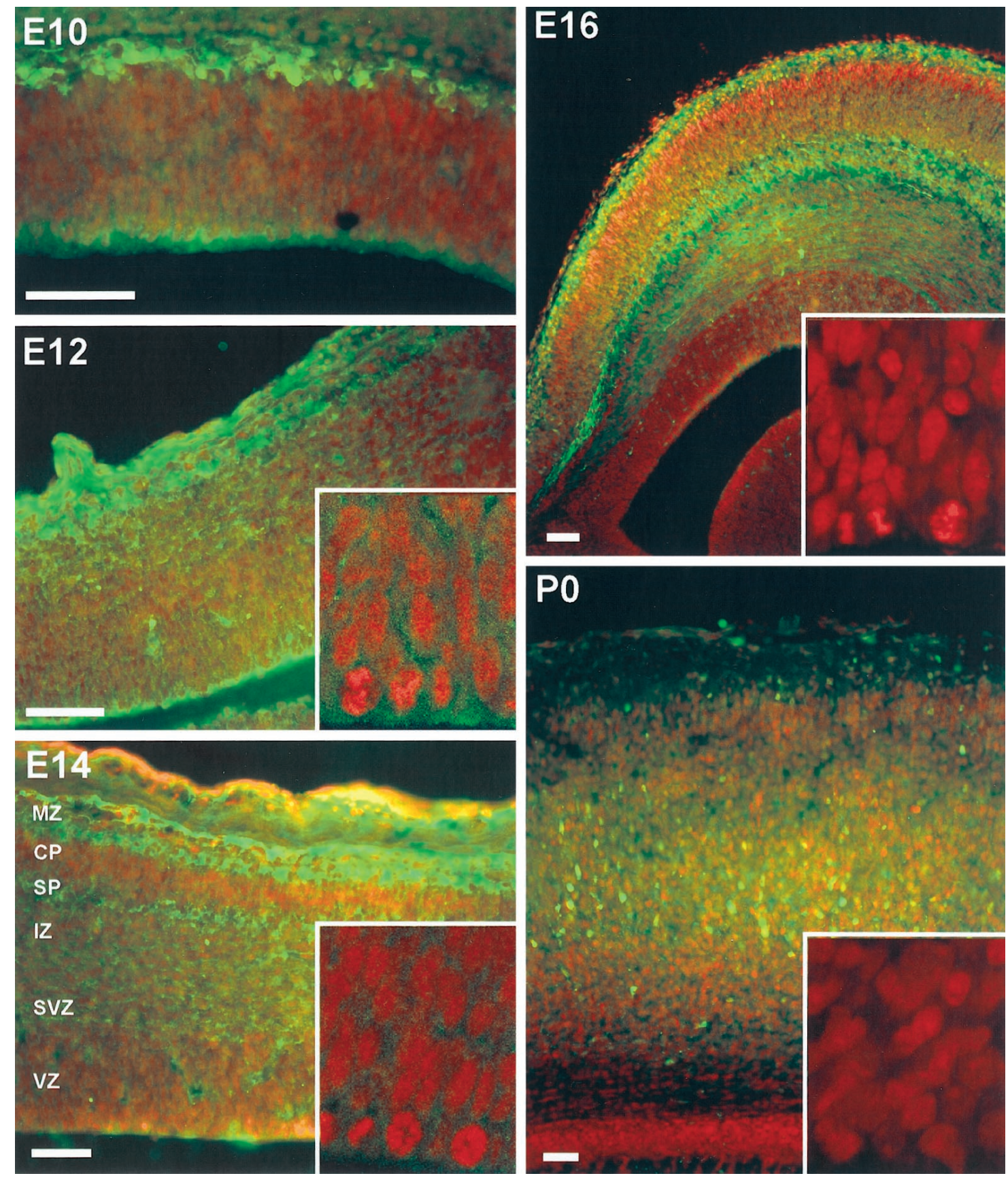

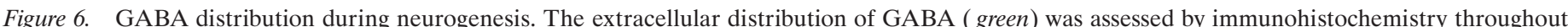

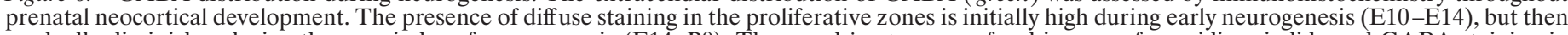

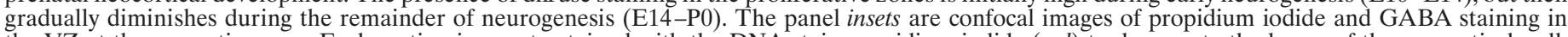

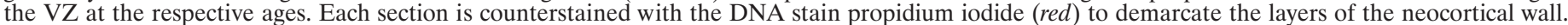

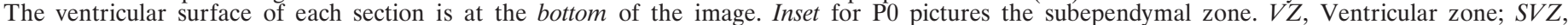
subventricular zone; $I Z$, intermediate zone; $S P$, subplate; $C P$, cortical plate; $M Z$, marginal zone. Scale bar, $50 \mu m$.

was still found throughout the proliferative zones. By E14, GABA staining was seen in the Cajal-Retzius cells of the marginal $(\mathrm{MZ})$, in the subplate (SP), and in the intermediate zones (IZ). The diffuse staining throughout the proliferative zones remained but was decreased compared to E10 and E12. At E16, many GABAergic cells were found in the MZ, cortical plate (CP), SP, and IZ, but GABA immunoreactivity in the proliferative zones was markedly reduced. Finally, at postnatal day 0 (P0), many cells in the neocortex were GABAergic, whereas no staining was detected in the proliferative SEZ.

Staining for glutamate in the neuroepithelium followed a similar course - it was high during early neurogenesis and diminished as neurogenesis progressed (Fig. 7). At E12, diffuse glutamate stain- ing was observed throughout the neocortical wall. However, on E14 and after, staining for glutamate gradually diminished in the proliferative epithelium. Thus, diff use staining for GABA and glutamate was observed in the proliferative zones early during neurogenesis and then diminished as neurogenesis proceeds, even though the number of GABA - and glutaminergic neurons in the cerebral wall increased.

\section{DISCUSSION}

Species-specific differences in laminar thickness and the relative contribution of neurons from the VZ and SVZ are well documented and are presumed to have been important for evolution. However, the genetic and molecular differences between the pro- 

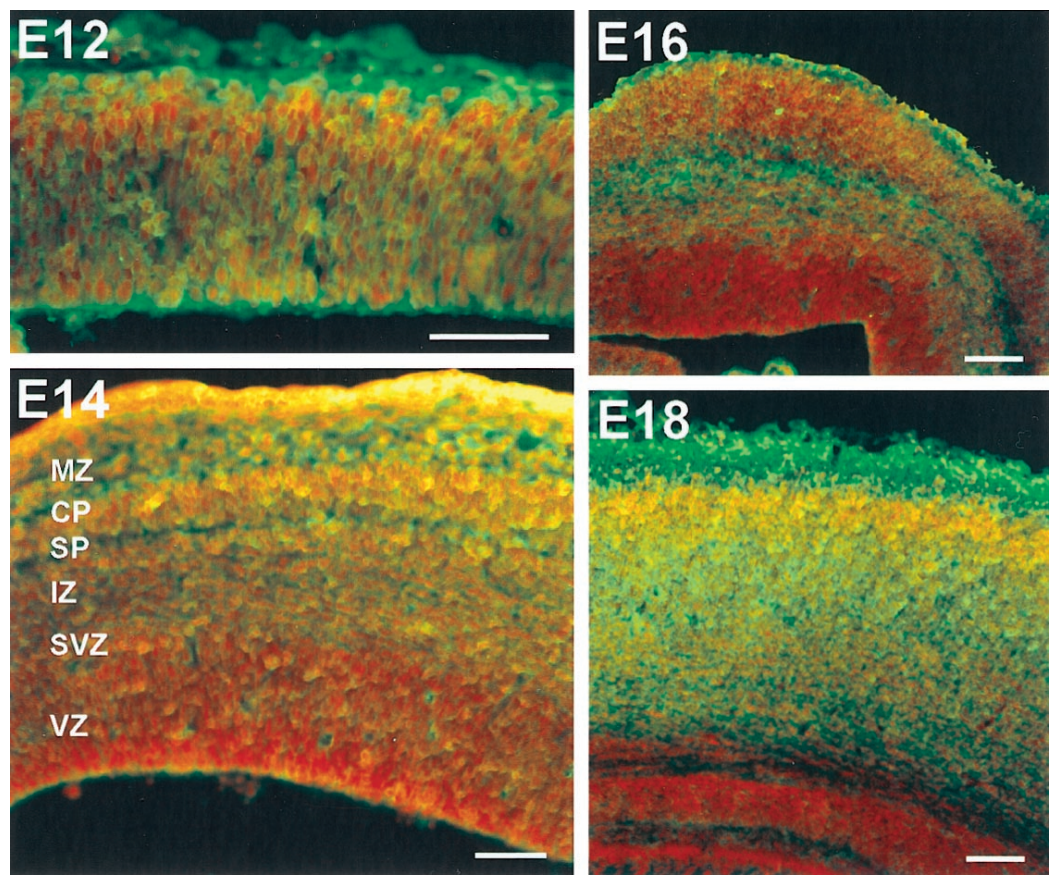

Figure 7. Glutamate distribution during neurogenesis. The distribution of glutamate ( green) during the period of neocortical neurogenesis was examined using immunohistochemistry. Diffuse staining throughout the neocortical wall was present at E12 and E14, but the comparative levels of glutamate staining in the proliferative zones subsided thereafter. On E16 and E18, high amounts of staining were only present in the marginal zone, subplate, and intermediate zone. Each section was counterstained with propidium iodide $($ red $)$ to elucidate the layers of the neocortical wall. The ventricular surface of each section is at the bottom of each image. Scale bar, $50 \mu \mathrm{m}$.

liferative zones that generate this diversity are not well understood. It has been suggested that changes in cortical size and shape are attributable to intrinsic differences between progenitor cells in the proliferative zones (McConnell, 1988; Parnavelas et al., 1991; Luskin et al., 1993; Kornack and Rakic, 1998). Here we propose that differential regulation of cell production in the VZ and SVZ by GABA and glutamate may both elucidate and exploit these intrinsic differences.

\section{GABA and glutamate differentially modulate cell proliferation in the VZ and SVZ}

Both the morphological separation between VZ and SVZ and the interkinetic nuclear migration particular to $\mathrm{VZ}$ progenitors were maintained in the neocortical slices, enabling us to analyze the proliferation of these two progenitor populations separately. In contrast to the stimulating effect of GABA and glutamate on proliferation in the VZ, these molecules substantially decreased proliferation in the SVZ. In addition, the effects of specific agonists and antagonists on $\mathrm{VZ}$ and $\mathrm{SVZ}$ progenitor proliferation indicate that GABA and glutamate act via $\mathrm{GABA}_{\mathrm{A}}$ and AMPA/kainate receptors as reported previously (LoTurco et al., 1995). Nevertheless, molecular differences between VZ and SVZ progenitors result in divergent proliferative behavior in response to GABA and glutamate.

In an attempt to explain the apparent discrepancy between the above results and those published previously that suggested that GABA and glutamate decrease neocortical proliferation (LoT urco et al., 1995; Antonopoulos et al., 1997), we analyzed the cumulative BrdU LI in the VZ and SVZ both together and separately. Because data presented previously are derived either from dissociated neocortical cells or counts from cultured slices without distinction between the proliferative zones, we reasoned that any differences between the VZ and SVZ proliferation in response to GABA and glutamate may have been masked when both progenitor populations were pooled. Indeed, consistent with previous reports, when the LI of both the VZ and SVZ are pooled after 16 or $24 \mathrm{hr}$ cumulative BrdU labeling, there is an overall decrease in LI as a result of the substantial reduction in SVZ proliferation. However GABA and glutamate cause opposite effects on VZ and SVZ proliferation when each population is analyzed separately.

\section{Modulation of proliferation during neurogenesis}

Whereas some species-specific size and regional differences depend on the number of founder progenitor cells and are determined early before the first neurons are born (Rakic, 1995; Haydar et al., 1999 c), here we have focused on the changes that affect neuron production during the phase of neurogenesis. Many parameters of progenitor proliferation are dynamically modulated during development of the mammalian brain (Fig. 8). For example, as neurogenesis in the cerebral wall proceeds, the VZ cell cycle duration progressively lengthens, and the proportion of progenitors that terminally divide to generate neurons also increases (Takahashi et al., 1996). These terminal divisions tend to decrease the size of the $\mathrm{VZ}$ until it is exhausted by the end of the neurogenetic interval. Also, whereas only the $\mathrm{VZ}$ is present at the start of neurogenesis, the SVZ appears later and its constituent progenitors still proliferate at the end of neurogenesis when the VZ progenitors cease proliferation.

The present results, which suggest that GABA and glutamate act in a similar manner to differentially modulate the proliferation of VZ and SVZ progenitors, are consistent with the depolarizing effects of both these neurotransmitters early in development (Mueller et al., 1983, 1984; Janigro and Schwartzkroin, 1988; Swann et al., 1989; LoTurco et al., 1995). In addition, the specific changes in proliferation induced by the neurotransmitters are concordant with the observed dynamics of the progenitor populations during neurogenesis (Fig. $8 A, B$ ). For example, high amounts of these neurotransmitters early during neurogenesis would promote both the rapid cycling of VZ progenitors and their re-entry into the cell cycle while at the same time inhibiting SVZ proliferation. Later, decreased levels of GABA and glutamate would cause a lengthening of the VZ cell cycle, promote VZ neurogenesis, and release the inhibition on SVZ proliferation. Indeed, previous work (Yan et al., 1992), and the staining for GABA and glutamate in Figures 6 and 7, suggest that proliferative zone levels of these two amino acids are high at early stages of neurogenesis and gradually decrease thereafter. Although precisely what causes this progressive decrease of GABA and glutamate levels in the proliferative zones during neurogenesis is unknown, the time at which this decrease occurs correlates with several processes underway in the developing neocortical wall. It may be significant that the bulk of cortical efferent and afferent axonal projections undergo extension through the IZ early in neurogenesis. The number of projections that reach their target structures then increases during neurogenesis, after which axons in the IZ become compacted. It may therefore be this compaction that acts as a barrier to further diffusion of GABA and glutamate later in neurogenesis. In 


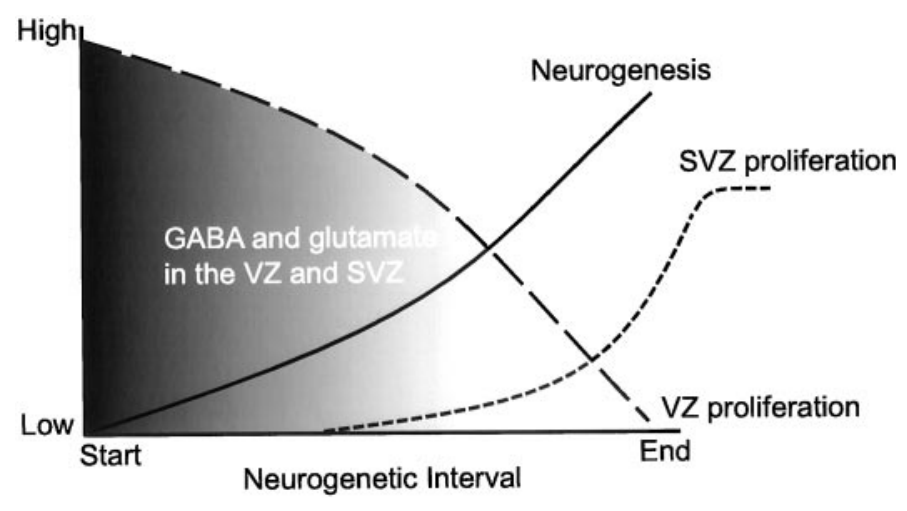

Figure 8. Proliferative gradients during neocortical histogenesis. Levels of GABA and glutamate (grayscale gradient) in the proliferative zones are high at the start of neurogenesis when VZ cells proliferate rapidly (long dashed line) and tend to reenter the cell cycle rather than become neurons, causing a slow rise in the amount of early neurogenesis (solid line). The decrease in GABA and glutamate levels throughout the remainder of the neurogenetic interval is concomitant with slower VZ proliferation, increased production of neurons until the VZ is exhausted of progenitors, and the emergence and predominance of the SVZ as a distinct proliferative compartment (short dashed line).

any case, the present results which show that GABA and glutamate differentially regulate progenitor proliferation are consistent with the observed proliferative dynamics during neurogenesis.

\section{Cell production in the developing cerebral wall}

The modulation of VZ and SVZ proliferative kinetics by GABA and glutamate could lead to changes in the number of postmitotic cells generated from these two progenitor populations. Because these neurotransmitters increase VZ progenitor proliferation, the VZ population would grow, enabling more postmitotic cells to be generated by the end of neurogenesis (Takahashi et al., 1997). In contrast, less SVZ proliferation would lead to fewer cells generated from the SVZ progenitor population. To test whether GABA and glutamate also influence the decision proliferative cells make after mitosis either to reenter the cell cycle or to exit and become postmitotic, we took advantage of the migration of newly generated cells into the neocortical wall, a process that is maintained in the neocortical slices (Haydar et al., 1999a). In the presence of either GABA or glutamate, the number of postmitotic cells that had migrated into the neocortical wall was dramatically reduced (Fig. 5). These fewer migrated $\mathrm{BrdU}^{+}$cells may have been caused by selective inhibitory effects of GABA and glutamate on migration or by the elimination of GABA- and glutamate-induced chemoattractive gradients. However, two lines of evidence support the notion that fewer migrated cells may instead be attributable to the proliferative behavior of progenitors. First, rather than inhibiting migration, both GABA (Behar et al., 1998) and glutamate (Komuro and Rakic, 1993; Behar et al., 1999) stimulate migration of newly generated neocortical neurons. Second, because the neurotransmitters were present for $4 \mathrm{hr}$ before addition of BrdU, if exogenous GABA and glutamate inhibited the directed migration of newly generated neurons, we would have expected to see an initial build-up of $\mathrm{BrdU}^{-}$cells in the $\mathrm{VZ}$ of treated slices that would have then decreased the GF in the VZ. Because no change from controls was seen in the VZ GF in GABA- and glutamate-treated slices (Fig. 2, Tables 1,2), exogenous neurotransmitter application is likely not to block cell cycle progression or to disrupt directed radial migration. Thus, the most parsimonious explanation of the results is that GABA and glutamate not only increase the kinetics of $\mathrm{VZ}$ proliferation, but may also inhibit neurogenesis by promoting symmetrical progenitor divisions and re-entry of daughter cells into the cell cycle. This inhibition of neurogenesis would cause an expansion of the $\mathrm{VZ}$ progenitor population and have the overall effect of increasing the final numbers of cells destined for the cerebral cortex.

While the lineal relationship between $\mathrm{VZ}$ and SVZ progenitors is not known, it is likely that the SVZ cells are initially derived from the VZ because the VZ is present first. Moreover, if the SVZ is being continually "seeded" by the VZ, our measured effects of GABA and glutamate on the VZ might affect SVZ size in an indirect manner by reducing the number of SVZ progenitors over time. Although we cannot rule out this possibility, the decrease in SVZ labeling index caused by GABA and glutamate reported here is an immediate and long-lasting influence on the SVZ cells that are present at the start of the experiment. Thus, despite the possible contamination of the SVZ by VZ cells, it is clear that GABA and glutamate differentially affect the proliferation of $\mathrm{VZ}$ and SVZ progenitors.

Regulation of cell cycle dynamics is considered a contributing mechanism for generating diversity within the neocortex, producing differences in the size of cortical areas and the thickness of cortical layers (Rakic, 1988; Dehay et al., 1993; Polleux et al., 1997). Recent studies have shown that although the cell cycle progressively slows as mouse neocortical neurogenesis proceeds (Takahashi et al., 1995a), the cell cycle of VZ progenitors in macaque monkey visual cortex transiently accelerates midway through neurogenesis during the time when layer IV, a relatively hypercellular cortical layer, is generated (Kornack and Rakic, 1998). Simultaneously, in other cortical areas, fewer cells destined for layer IV are produced. These areal differences during layer generation may be regulated by localized and transient increases in GABA and glutamate in the progenitor populations at the correct time during neurogenesis.

The modulation of progenitor proliferation by neurotransmitters may also explain the pathogenesis of certain neocortical malformations. For example, the number of terminal progenitor divisions during neocortical neurogenesis is decreased in the Trisomy 16 mouse (Haydar et al., 1999b), a model for Down's syndrome that has three rather than two copies of GluR5, a gene encoding an AMPA/kainate glutamate receptor (Reeves et al., 1986; Holtzman and Epstein, 1992). This decreased neurogenesis leads to expansion of the VZ population and a concomitant transient delay in neocortical growth (Haydar et al., 1999b). The amino acids GABA and glutamate are present at the right times and exert appropriate effects on the progenitor populations to provide a plausible mechanism for all of these instances of neurogenetic regulation.

Several studies in rodents have shown that the length of $\mathrm{S}$-phase is relatively conserved throughout neurogenesis (Reznikov and van der Kooy, 1995; Takahashi et al., 1995a) and that changes in the duration of G1 phase are mostly responsible for the increase in the overall cycle duration (Takahashi et al., 1995a). However, there are also examples of modulation of S-phase duration that are consistent with the GABA and glutamate-induced changes reported here. For example, there is a transient threefold increase in S-phase duration during monkey neurogenesis (Kornack and Rakic, 1998), and exogenous vasoactive intestinal peptide has been shown to shorten S-phase by $50 \%$ when applied to whole cultured mouse embryos (Gressens et al., 1998). Taken together, these results suggest that, while normally relatively constant during mouse neurogenesis, the length of S-phase can be modulated and that this added control may account for some of the differences in cortical growth between species.

Several recent studies have indicated that significant differences exist between neural progenitors during early forebrain development. The lineage-dependent and selective response of progenitor subpopulations to environmental cues (Eagleson et al., 1998) and the different kinetic and developmental histories of FGF and EGF-responsive neural stem cells (Kuhn et al., 1997; Martens et al., 2000) point to the emergence of particular molecular traits during early phases of forebrain development. 
Similarly, this study suggests that the differential effects of GABA and glutamate on VZ and SVZ progenitors may be attributable to variations in the signaling mechanisms that control their proliferation. Because the SVZ appears immediately juxtaposed to the VZ some time after VZ amplification and postmitotic cell generation has already started, this secondary proliferative compartment may in fact be generated from VZ progenitors. The molecular differences between VZ and SVZ cells described here should therefore be specified soon after these "SVZ-generating" divisions and may act to facilitate the adoption of the distinct role and new position of SVZ progenitors. Nevertheless, now that distinct differences between progenitors in the cerebral wall have been identified mechanistically, the road is paved for elucidation of the molecular mechanisms controlling proliferation of progenitor groups. An appreciation of such mechanisms is crucial for understanding normal and pathological cortical growth and may lead to the development of strategies for neural stem cell production and utilization as well as the treatment of diseases affecting higher brain function.

\section{REFERENCES}

Altman J (1969) Autoradiographic and histological studies of postnatal neurogenesis. IV Cell proliferation and migration in the anterior forebrain, with special reference to persisting neurogenesis in the olfactory bulb. J Comp Neurol 137:433-458.

Antonopoulos J, Pappas IS, Parnavelas JG (1997) Activation of the $\mathrm{GABA}_{\mathrm{A}}$ receptor inhibits the proliferative effects of bFGF in cortical progenitor cells. Eur J Neurosci 9:291-298.

Bao ZZ, Cepko CL (1997) The expression and function of Notch pathway genes in the developing rat eye. J Neurosci 17:1425-1434.

Behar TN, Schaffner AE, Scott CA, O'Connell C, Barker JL (1998) Differential response of cortical plate and ventricular zone cells to GABA as a migration stimulus. J Neurosci 18:6378-6387.

Behar TN, Scott CA, Greene CL, Wen X, Smith SV, Maric D, Liu Q-Y, Colton CA, Barker JL (1999) Glutamate acting at NMDA receptors stimulates embryonic cortical neuronal migration. J Neurosci 19:4449-4461.

Boulder Committee Report (1970) Embryonic vertebrate central nervous system: revised terminology. Anat Rec 166:257-262.

Cameron HA, Hazel TG, McKay RD (1998) Regulation of neurogenesis by growth factors and neurotransmitters. J Neurobiol 36:287-306.

Cattaneo E, McKay R (1990) Proliferation and Differentiation of neuronal stem cells regulated by nerve growth factor. Nature 347:762-765.

Cavanagh JF, Mione MC, Pappas IS, Parnavelas JG (1997) Basic fibroblast growth factor prolongs the proliferation of rat cortical progenitor cells in vitro without altering their cell cycle parameters. Cereb Cortex 7:293-302.

Dehay C, Giroud P, Berland M, Smart I, Kennedy H (1993) Modulation of the cell cycle contributes to the parcellation of the primate visual cortex. Nature 366:464-466.

Doetsch F, Caille I, Lim DA, Garcia-Verdugo JM, Alvarez-Buylla A (1999) Subventricular zone astrocytes are neural stem cells in the adult mammalian brain. Cell 97:703-716.

Eagleson KL, Daigneau L, Levitt P (1998) The role of ErbB receptor signaling in cell fate decisions by cortical progenitors: evidence for a biased, lineage-based responsiveness to different ligands. Mol Cell Neurosci 12:349-362.

Fiszman ML, Borodinsky LN, Neale JH (1999) GABA induces proliferation of immature cerebellar granule cells grown in vitro. Brain Res Dev Brain Res 115:1-8.

Furukawa T, Morrow EM, Cepko CL (1997) Crx, a novel otx-like homeobox gene, shows photoreceptor-specific expression and regulates photoreceptor differentiation. Cell 91:531-541.

Gensburger C, Labourdette G, Sensenbrenner M (1987) Brain basic fibroblast growth-factor stimulates the proliferation of rat neuronal precursor cells-in vitro. FEBS Lett 217:1-5.

Ghosh A, Greenberg ME (1995) Distinct roles for bFGF and NT-3 in the regulation of cortical neurogenesis. Neuron 1:89-103.

Gressens P, Paindaveine B, Hill JM, Evrard P, Brenneman DE (1998) Vasoactive intestinal peptide shortens both G1 and S phases of neura cell cycle in whole postimplantation cultured mouse embryos. Eur J Neurosci 10:1734-1742.

Hajihosseini M, Iavachev L, Price J (1993) Evidence that retroviruses integrate into post-replication host DNA. EMBO J 13:4969-4974.

Haydar TF, Bambrick LL, Krueger BK, Rakic P (1999a) Organotypic slice cultures for analysis of proliferation, cell death, and migration in the embryonic neocortex. Brain Res Brain Res Protoc 4:425-437.

Haydar TF, Nowakowski RS, Yarowsky PJ, Krueger BK (1999b) Role of founder cell deficit and delayed neuronogenesis in microencephaly of the trisomy 16 mouse. J Neurosci 20:4156-4164.
Haydar TF, Kuan C-Y, Flavell RA, Rakic P (1999c) The role of cell death in regulating the size and shape of the mammalian forebrain. Cereb Cortex 9:621-626.

Holtzman DM, Epstein CJ (1992) The molecular genetics of Down syndrome. In: Molecular genetic medicine, Vol 2 (Friedmann T, ed), pp 105-120. San Diego: Academic.

Janigro D, Schwartzkroin PA (1988) Effects of GABA and baclofen on pyramidal cells in the developing rabbit hippocampus: an "in vitro" study. Brain Res 469:171-184.

Komuro H, Rakic P (1993) Modulation of neuronal migration by NMDA receptors. Science 260:95-97.

Kornack DR, Rakic P (1998) Changes in cell-cycle kinetics during the development and evolution of primate neocortex. Proc Natl Acad Sci USA 95:1242-1246.

Kuhn HG, Winkler J, Kempermann G, Thal LJ, Gage FH (1997) Epidermal growth factor and fibroblast growth factor- 2 have different effects on neural progenitors in the adult rat brain. J Neurosci 17:5820-5829.

Lidow MS, Rakic P (1995) Neurotransmitter receptors in the proliferative zones of the developing primate occipital lobe. J Comp Neurol 360:393-402.

LoTurco JJ, Owens DF, Heath MJ, Davis MB, Kriegstein AR (1995) GABA and glutamate depolarize cortical progenitor cells and inhibit DNA synthesis. Neuron 15:1287-1298.

Luskin MB, Parnavelas JG, Barfield JA (1993) Neurons, astrocytes, and oligodendrocytes of the rat cerebral cortex originate from separate progenitor cells: An ultrastructural analysis of clonally related cells. J Neurosci 13:1730-1750.

Martens DJ, Tropepe V, van Der Kooy D (2000) Separate proliferation kinetics of fibroblast growth factor-responsive and epidermal growth factor-responsive neural stem cells within the embryonic forebrain germinal zone. J Neurosci 20:1085-1095.

McConnell SK (1988) Fates of visual cortical neurons in the ferret after isochronic and heterochronic transplantation. J Neurosci 8:945-974.

Mueller AL, Chesnut RM, Schwartzkroin PA (1983) Actions of GABA in developing rabbit hippocampus: an in vitro study. Neurosci Lett 39:193-198

Mueller AL, Taube JS, Schwartzkroin PA (1984) Development of hyperpolarizing inhibitory postsynaptic potentials and hyperpolarizing response to gamma-aminobutyric acid in rabbit hippocampus studied in vitro. J Neurosci 4:860-867.

Parnavelas JG, Barfield JA, Franke E, Luskin MB (1991) Separate progenitors give rise to pyramidal and nonpyramidal neurons in the rat telencephalon. Cereb Cortex 1:463-468.

Pear WS, Scott ML, Nolan GP (1996) Generation of high titre, helperfree retroviruses by transient transfection. In: Methods in molecular medicine: gene therapy protocols (Robbins P, ed) pp 41-57. Totowa, NJ: Humana.

Polleux F, Dehay C, Moraillon B, Kennedy H (1997) Regulation of neuroblast cell-cycle kinetics plays a crucial role in the generation of unique features of neocortical areas. J Neurosci 17:7763-7783.

Rakic P (1988) Specification of cerebral cortical areas Science 241:170-176.

Rakic P (1995) A small step for the cell, a giant leap for mankind: a hypothesis of neocortical expansion during evolution. Trends Neurosci 18:383-388.

Reeves RH, Gearhart JD, Littlefield JW (1986) Genetic basis for a mouse model of Down syndrome. Brain Res Bull 16:803-814.

Reynolds BA, Weiss S (1992) Generation of neurons and astrocytes from isolated cells of the adult mammalian nervous system. Science 255:1707-1710.

Reznikov K, van der Kooy D (1995) Variability and partial synchrony of the cell cycle in the germinal zone of the early embryonic cerebral cortex. J Comp Neurol 360:536-54.

Schambra UB, Lauder JM, Silver J (1992) Atlas of the prenatal mouse brain. San Diego: Academic.

Schwartz ML, Meinecke DL (1992) Early expression of GABAcontaining neurons in the prefrontal and visual cortices of rhesus monkeys. Cereb Cortex 2:16-37.

Sidman RL, Rakic P (1973) Neuronal migration, with special reference to developing human brain: a review. Brain Res 62:1-35.

Sidman RL, Miale IL, Feder N (1959) Cell Proliferation in the primitive ependymal zone: an autoradiographic study of histogenesis in the nervous system. Exp Neurol 1:322-333.

Smart I (1961) The subependymal layer of the mouse brain and its cell production as shown by radioautography after thymidine- $\mathrm{H}^{3}$ injection. J Comp Neurol 116:325-338.

Swann JW, Brady RJ, Martin DL (1989) Postnatal development of GABA-mediated synaptic inhibition in rat hippocampus. Neuroscience 28:551-561.

Takahashi T, Nowakowski RS, Caviness Jr VS (1995a) The cell cycle of the pseudostratified ventricular epithelium of the embryonic murine cerebral wall. J Neurosci 15:6046-6057.

Takahashi T, Nowakowski RS, Caviness Jr VS (1995b) Early ontogeny of the secondary proliferative population of the embryonic murine cerebral wall. J Neurosci 15:6058-6068.

Takahashi T, Nowakowski RS, Caviness Jr VS (1996) The leaving or Q 
fraction of the murine cerebral proliferative epithelium: a general model of neocortical neuronogenesis. J Neurosci 16:6183-6196.

Takahashi T, Nowakowski RS, Caviness Jr VS (1997) The mathematics of neocortical neuronogenesis. Dev Neurosci 19:17-22.

Takahashi T, Bhide PG, Goto T, Miyama S, Caviness Jr VS (1999) Proliferative behavior of the murine cerebral wall in tissue culture: cell cycle kinetics and checkpoints. Exp Neurol 156:407-417.

Vaccarino FM, Schwartz ML, Hartigan D, Leckman JF (1995) Basic fi-broblast growth factor increases the number of excitatory neurons containing glutamate in the cerebral cortex. Cereb Cortex 1:64-78.

Vaccarino FM, Schwartz ML, Raballo R, Nilsen J, Rhee J, Zhou M,
Doetschman T, Coffin JD, Wyland JJ, Hung YT (1999) Changes in cerebral cortex size are governed by fibroblast growth factor during embryogenesis. Nat Neurosci 3:246-253.

Van Eden CG, Mrzljak L, Voorn P, Uylings HB (1989) Prenatal development of GABA-ergic neurons in the neocortex of the rat. J Comp Neurol 289:213-227.

Walsh CA (1999) Genetic malformations of the human cerebral cortex. Neuron 23:19-29.

Yan XX, Zheng DS, Garey LJ (1992) Prenatal development of GABAimmunoreactive neurons in the human striate cortex. Brain Res Dev Brain Res 65:191-204. 